\title{
Citologia de Tzanck: redescobrindo uma antiga ferramenta diagnóstica
}

\author{
Tzanck smears: an old but useful diagnostic tool
}

\author{
Moema Mignac Cumming Brito ${ }^{1}$ \\ Darlene Arruda ${ }^{3}$ \\ Ana Maria Roselino ${ }^{5}$
}

\author{
Daniela Chaves Tarquínio ${ }^{2}$ \\ Roberto Silva Costa ${ }^{4}$
}

\begin{abstract}
Resumo: A citologia de Tzanck consiste em método simples e confiável para o diagnóstico de dermatoses virais, parasitárias, autoimunes e tumorais. Para exemplificar o emprego do teste de Tzanck em lesões vésico-bolhosas, um caso de pênfigo vulgar é descrito, cuja citologia e imunofluorescência direta, utilizando-se esfregaço coletado de lesão oral, confirmaram o diagnóstico de forma rápida e fácil.
\end{abstract}

Palavras-chave: Citologia; Imunofluorescência; Pênfigo

\begin{abstract}
Tzanck smears can be used for the diagnosis of cutaneous infections, autoimmune disorders and cutaneous tumors. To exemplify its use, we report a case of a female patient with pemphigus vulgaris whose diagnosis was confirmed by positive direct immunofluorescence and conventional cytology using smears obtained by scraping the cheek mucosa.

Keywords: Cytology; Fluorescent antibody technique; Pemphigus
\end{abstract}

A citologia, que estuda as células individuais, suas características intrínsecas e suas funções, é uma ciência relativamente nova. George Papanicolaou é considerado o pai da citologia esfoliativa; porém, em 1947, foi Tzanck quem utilizou pela primeira vez a citologia para diagnóstico, empregando-a em dermatoses vésico-bolhosas, particularmente no herpes simplex. Os dermatologistas pouco têm utilizado a citodiagnose no seu cotidiano, embora, em mãos experientes, o exame de esfregaço cutâneo ou de mucosa possa ser simples, rápido, barato e confiável para o diagnóstico de muitas doenças dermatológicas, das mais variadas etiologias. Seu uso tem se restringido à pesquisa de células escamosas multinucleadas sugestivas de inclusão viral em lesões de mucosa oral ou quando se suspeita de eczema vacinatum. ${ }^{1,2}$
Observando-se achados citológicos característicos, pode-se realizar o diagnóstico de genodermatoses, infecções cutâneas, doenças autoimunes, além de tumores (Quadro 1). Em relação às dermatoses bolhosas, as células acantolíticas, demonstradas no esfregaço de lesão mucosa do pênfigo vulgar (PV), receberam a denominação de células de Tzanck. ${ }^{3}$ A presença de células acantolíticas é indicativa, mas não específica do PV. Alguns autores têm procurado avaliar o papel da imunofluorescência direta (IFD) no esfregaço de Tzanck para o diagnóstico do PV. Os resultados da IFD, realizada no esfregaço citológico e em biópsia cutânea convencional de um mesmo grupo de pacientes, mostraram-se concordantes para ambas as amostras. ${ }^{4}$

Para demonstrar o emprego do teste de Tzanck em dermatose bolhosa, a seguir descrevemos um caso

Aprovado pelo Conselho Editorial e aceito para publicação em 22.12.2008

* Trabalho realizado na Universidade de São Paulo (USP) - São Paulo (SP) e no Hospital das Clínicas, Faculdade de Medicina de Ribeirão Preto (FMRP-USP) Ribeirão Preto (SP), Brasil.

Conflito de interesse: Nenhum / Conflict of interest: None

Suporte financeiro: / Financial funding: Faepa (Fundação de Apoio ao Ensino, Pesquisa e Assistência) e Hospital das Clínicas (FMRP-USP).

MD - Especialista em Dermatologia, Hospital das Clínicas, Faculdade de Medicina de Ribeirão Preto (FMRP-USP) - Ribeirão Preto (SP), Brasil.

MD - Especialista em Dermatologia, mestranda, Faculdade de Medicina de Ribeirão Preto (FMRP-USP) - Ribeirão Preto (SP), Brasil.

MD (in memoriam) - Médica assistente, Departamento de Patologia, Hospital das Clínicas, Faculdade de Medicina de Ribeirão Preto (FMRP-USP) - Ribeirão Preto (SP), Brasil.

MD, PhD - Professor titular, Departamento de Patologia, Hospital das Clínicas, Faculdade de Medicina de Ribeirão Preto (FMRP-USP) - Ribeirão Preto (SP), Brasil MD, PhD - Professora associada, Divisão de Dermatologia, Departamento de Clínica Médica, Faculdade de Medicina de Ribeirão Preto (FMRP-USP) - Ribeirão Preto (SP), Brasil.

(C)2009 by Anais Brasileiros de Dermatologia 
QuADro 1: Principais aplicações do citodiagnóstico na dermatologia

\begin{tabular}{|c|c|}
\hline Dermatose & Achados citológicos \\
\hline \multicolumn{2}{|l|}{ Genodermatoses } \\
\hline Doença de Hailey-Hailey & Células acantolíticas, nucléolo normal \\
\hline Doença de Darier & Corpos redondos \\
\hline \multicolumn{2}{|l|}{ Infecções cutâneas } \\
\hline Leishmaniose & Corpos de Leishman-Donovan, células de Wright \\
\hline Herpes simples - varicela-zóster & Células multinucleadas balonizantes \\
\hline Doença da mão, pé e boca & Células com núcleo sincicial \\
\hline Molusco contagioso & Corpos de Henderson-Patterson \\
\hline \multicolumn{2}{|l|}{ Doenças imunológicas } \\
\hline Pênfigo vulgar & Células acantolíticas, nucléolos apagados \\
\hline $\begin{array}{l}\text { Penfigoide bolhoso, síndrome de Stevens-Johnson, } \\
\text { líquen plano erosivo }\end{array}$ & Células não acantolíticas, muitos leucócitos \\
\hline Necrólise Epidérmica Tóxica (NET) & Células basais necróticas, leucócitos, fibroblastos \\
\hline SSSS* & Células acantolíticas disceratósicas, pouca inflamação \\
\hline \multicolumn{2}{|l|}{ Tumores cutâneos } \\
\hline $\begin{array}{l}\text { CBC, } * * \text { CEC, } * * * \text { doença de Paget, eritroplasia } \\
\text { de Queyrat } \\
\text { Mastocitoma, histiocitose X }\end{array}$ & Células tumorais correspondentes ao tumor \\
\hline
\end{tabular}

Fonte modificada: Gupta LK et al. ${ }^{3}$ e Ruocco V et al. ${ }^{1}$

*Síndrome da pele escaldada estafilocócica; **Carcinoma basocelular; ***Carcinoma espinocelular

clínico, cuja citologia e IFD, utilizando-se esfregaço coletado de lesão oral, confirmaram o diagnóstico de PV. Resumidamente, paciente do sexo feminino, 49 anos, procedente da região nordeste do estado de São Paulo, há dois anos vinha apresentando lesões erosivas na mucosa oral, associadas à odinofagia, além de lesões na mucosa vaginal. Após três meses, surgiram bolhas tensas de conteúdo hialino no tegumento. Ao exame dermatológico apresentava lesões exulceradas no palato duro, na mucosa jugal e na mucosa gengival perialveolar, além de lesões lenticulares a numulares erodidas nas axilas, dorso, abdome e região inguinal. O sinal de Nikolsky estava presente. Colheu-se raspado de lesão oral com espátula de madeira seccionada longitudinalmente, dispondo-o na forma de esfregaço em duas lâminas. Uma delas foi imediatamente fixada em etanol $70^{\circ}$ para a realização da citologia convencional, e a outra foi estocada em freezer comum para a realização da IFD. O esfregaço citológico mostrou achados compatíveis com pênfigo, assim como a IFD evidenciou depósito de anti-IgG entre os queratinócitos. Realizou-se biópsia cutânea, que, pelo achado de acantólise suprabasal, confirmou o diagnóstico de PV. Pela queixa de odinofagia, a paciente foi submetida à endoscopia digestiva alta, sendo constatada esofagite crônica acantolítica na amostra de biópsia esofágica (Figura 1).

Em estágios precoces do PV, o esfregaço de Tzanck mostra-se uma ferramenta muito útil, pois se

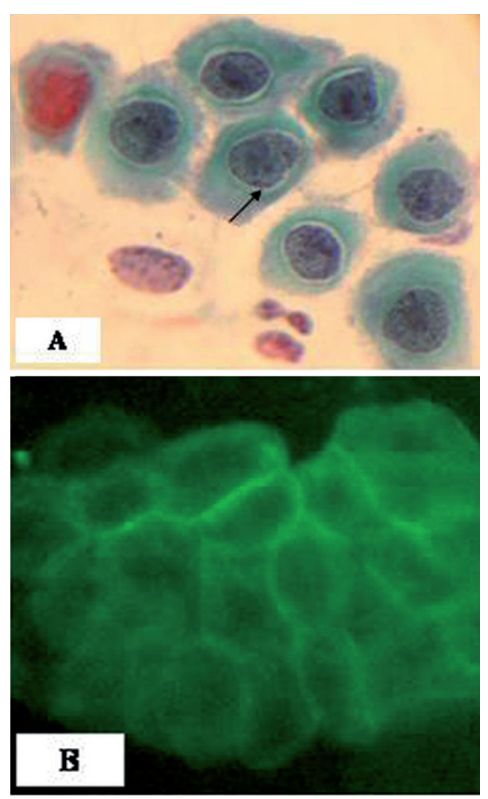

Figura 1: A. Esfregaço da mucosa oral corado com Hematoxilina/Shorr: presença de células escamosas acantolíticas com núcleo arredondado, aumentado de volume, nucléolos inconspícuos, múltiplos, com halo claro perinuclear (seta), e polimorfonucleares, compatível com pênfigo $(40 \mathrm{xx})$. B. IFD realizada no esfregaço da mucosa oral: depósito de anti-IgG entre os queratinócitos, confirmando o diagnóstico de pênfigo (20xx).

C. Amostra de esôfago, corada com H\&E, mostrando acantólise suprabasal (seta) compatível com PV (40xx) 
sabe que muitas vezes o paciente inicia o quadro de PV com lesões mucosas, como relatado nesta paciente, e o estabelecimento do diagnóstico deve ser feito o mais rápido possível para que o tratamento possa ser iniciado, tendo em vista a gravidade do quadro. $\mathrm{O}$ esfregaço citológico, também utilizado para a realização da IFD, é particularmente importante para o diagnóstico do PV nas regiões anatômicas de difícil acesso, como as lesões da cavidade oral e da região genital. Alguns autores ressaltam que a IFD tem valor prognóstico e que o achado da IFD positiva durante a remissão do pênfigo pode significar recaída em potencial quando comparada à IFD negativa. ${ }^{4,5}$

Enfatiza-se que o emprego da citologia de Tzanck nas dermatoses bolhosas pode estender-se às lesões cutâneas do pênfigo foliáceo, endêmico no

\section{REFERÊNCIAS}

1. Ruocco V, Ruocco E. Tzanck smear, an old test for the new millenium: when and how? Int $\mathrm{J}$ Dermatol. 1999;38:830-4.

2. Rao GRR, Chalam KV, Prasad GP, Sarnathan M, Kumar HKY. Mini outbreak of Kaposi's varicelliform eruption in skin ward: a study of five cases. Indian J Dermatol Venereol Leprol. 2007;73:33-5.

3. Gupta LK, Singhi MK. Tzanck smear: a useful diagnostic tool. Indian J Dermatol Venereol Leprol. 2005; 71:295-9.

4. Aithal V, Kini U, Jayaseelan E. Role of direct immunofluorescence on Tzanck smears in pemphigus vulgaris. Diagn Citopathol. 2007;35:403-7.

5. Ratnam KV, Kang BK. Pemphigus in remission: value of negative direct immunofluorescence in management. J Am Acad Dermatol. 1994;30:547-50.

6. Chiossi MPV, Roselino AMF. Endemic pemphigus foliaceus (Fogo selvagem): a series from the
Brasil. ${ }^{6}$ Coletando-se amostras de pele ou de mucosa em duplicata, somada à citologia, a IFD também realizada no esfregaço pode ser aplicada para avaliação rotineira de diagnóstico e de prognóstico, já que é um método barato e fácil de ser executado. Nesse sentido, locais com recursos laboratoriais mais precários podem beneficiar-se de tal técnica, visto que a IFD realizada em biópsia cutânea requer equipamentos mais caros, como o uso de micrótomos, e técnicos especializados.

Dessa forma, fica claro que a citologia, apesar de ser um método antigo, ainda tem espaço para o diagnóstico de muitas dermatoses, ${ }^{7}$ numa era em que os procedimentos diagnósticos em todas as especialidades da medicina estão se multiplicando rapidamente, tornando-se cada vez mais refinados e também cada vez mais onerosos aos pacientes.

Northeastern region of the State of São Paulo, Brazil, 1973-1998. Rev Inst Med Trop Sao Paulo. 2001;43:59-62.

7. Durdu M, Baba M, Seçkin D. The value of Tzanck smear test in diagnosis of erosive, vesicular, bullous, and pustular skin lesions. J Am Acad Dermatol. 2008;59:958-64.

\author{
ENDEREÇO PARA CORRESPONDÊNCIA / MAILING ADDRESS: \\ Ana Maria Roselino \\ Departamento de Clínica Médica - FMRP-USP \\ Av. Bandeirantes, 3.900 \\ 14049900 - Ribeirão Preto SP \\ Tel./Fax: +551636330236 \\ E-mail: amfrosel@fmrp.usp.br
}

